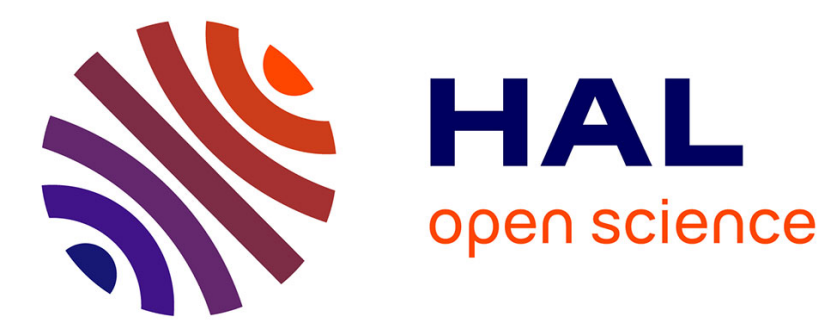

\title{
ATOM - PROBE ANALYSIS OF YBa2 Cu3 O7-x - SINGLE CRYSTALS
}

\author{
M. Leisch, M. Eisl, E. Schweiger, G. Leising
}

\section{To cite this version:}

M. Leisch, M. Eisl, E. Schweiger, G. Leising. ATOM - PROBE ANALYSIS OF YBa2 Cu3 O7-x - SINGLE CRYSTALS. Journal de Physique Colloques, 1989, 50 (C8), pp.C8-481-C8-486. 10.1051/jphyscol:1989882 . jpa-00229980

\section{HAL Id: jpa-00229980 https://hal.science/jpa-00229980}

Submitted on 1 Jan 1989

HAL is a multi-disciplinary open access archive for the deposit and dissemination of scientific research documents, whether they are published or not. The documents may come from teaching and research institutions in France or abroad, or from public or private research centers.
L'archive ouverte pluridisciplinaire HAL, est destinée au dépôt et à la diffusion de documents scientifiques de niveau recherche, publiés ou non, émanant des établissements d'enseignement et de recherche français ou étrangers, des laboratoires publics ou privés. 


\title{
ATOM - PROBE ANALYSIS OF $\mathrm{YBa}_{2} \mathrm{Cu}_{3} \mathrm{O}_{7-x}$ - SINGLE CRYSTALS
}

\author{
M. LEISCH, M. EISL, E. SCHWEIGER and G. LEISING \\ Institut für Festkörperphysik, University of Technology Graz \\ petersgasse 16, A-8010 Graz, Austria
}

\begin{abstract}
Résumé - Des expérimentations supplémentaires à l'aide de spectromètres d'ion de champ ont été effectuées pour caractériser et optimiser les conditions de préparation des monocristaux $\mathrm{YBa}_{2} \mathrm{Cu}_{3} \mathrm{O}_{7-x}$. L'analyse de profil en profondeur de petites aiguilles détachées démontre des fluctuations distinctes des concentrations des éléments principaux lesquelles sont en rapport avec la structure stratifièe de la matière. La composition déterminée par de expériences est en concordance avec la physe 1:2:3 qui. était escomptée. Des traces de fondants utilisés de plus dans la culture du cristal, tel que $\mathrm{PbCl}_{2}$, peuvent être détectées près de la surface.
\end{abstract}

Abstract - Complementary atom-probe measurements have been carried out to characterize and to optimize the preparation conditions of $\mathrm{YBa}_{2} \mathrm{Cu}_{3} \mathrm{O}_{7-x}$ - single crystals. The depth profiling analysis of cleaved off small needles shows distinct fluctuations of the main components connected to the layer structure of the material. The bulk composition as determined from atom-probe spectra is generally in agreement with the expected 1:2:3 phase. Additionally used flux media in the growth procedure like $\mathrm{PbCl}_{2}$ can be found embedded in near surface layers.

\section{1 - INTRODUCTION}

Since the discovery of one of the most thoroughly investigated high temperature superconductor material $\mathrm{YBa}_{2} \mathrm{Cu}_{3} \mathrm{O}_{7-\mathrm{x}}(0<\mathrm{x}<1) / 1 /$ it was realized that it is remarkably easy to prepare ceramic samples with transition temperatures above $90 \mathrm{~K}$. In contrast, it is much more difficult to produce single crystals /2/. Nevertheless, single crystals with suitable dimensions for transport, magnetic and optical measurements are of basic interest. The problems in crystal growth of $\mathrm{YBa}_{2} \mathrm{Cu}_{3} \mathrm{O}_{7-x}$ are based on its limited thermal and chemical stability and on its low solubility in appropriate flux media. Initial growth experiments were performed from a melt of the pseudoternary system $\mathrm{CuO}-\mathrm{BaCuO}_{2}-\mathrm{YBa}_{2} \mathrm{Cu}_{3} \mathrm{O}_{7}$. Appropriate amounts of the components were grounded, pelletized and melted in alumina crucibles, lined by gold sheets. Using the wetting and creeping of the melt on the gold surface, platelike crystals up to a dimension of $1 \times 1 \times 0.1 \mathrm{~mm}$ can be found in the gaps between the metal sheets /3/. The previous characterization of the obtained crystals has been done by electron microprobe analysis, $X$-ray diffraction and by transport measurements. Preliminary atom-probe field-ion microscopic investigations performed on high temperature superconductors were successful in applying the technique to these new material /4-7/. To obtain additional information about microcomposition and to help to optimize the preparation conditions complementary atomprobe studies have been carried out. 


\section{2 - EXPERIMENTAL}

The starting point in the sample preparation has been a preselection of suitable crystals from parts of the charge as removed from the crucible. A typical arrangement of the platelike crystals as grown in the cavities can be seen in the electron micrograph in fig.1. The composition of the crystals has been checked by electron microprobe analysis. The Y:Ba:Cu ratios were 1:2:3 in each crystal within the accuracy of the electron microprobe measurement. The rest of the melt e.g. in the corners of the micrograph contains mainly cuo.

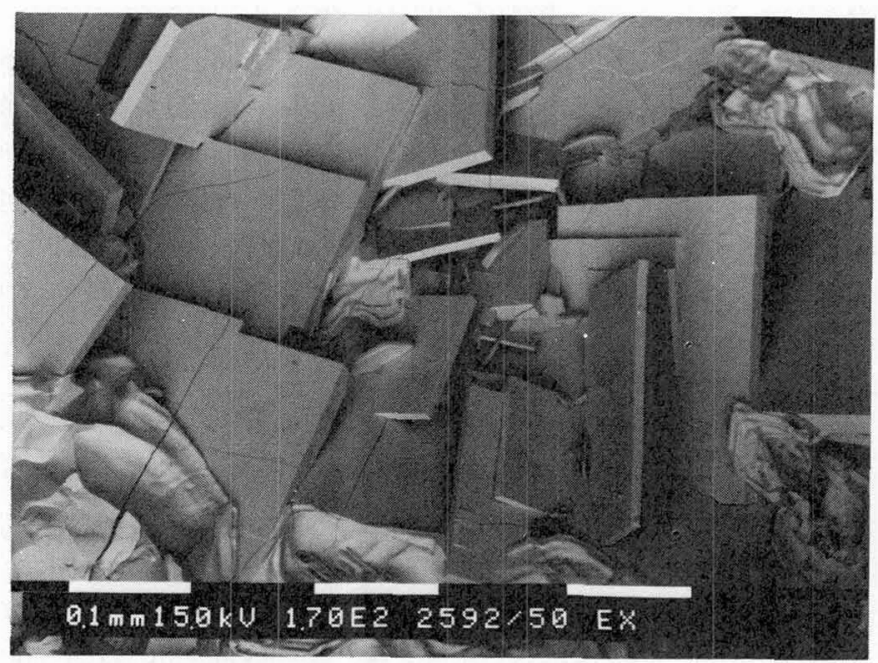

Fig.1 - Scanning electron micrograph of $\mathrm{YBa}_{2} \mathrm{Cu}_{3} \mathrm{O}_{7-x}$ single crystals as grown from the melt.

Selected crystals have been removed carefully. In order to prove the quality of the single crystals they are investigated by $X$-ray diffraction in the Lave geometry. Fig. 2 shows the Lave diffraction pattern of a sample in transmission mode with the beam parallel to the 001-direction.

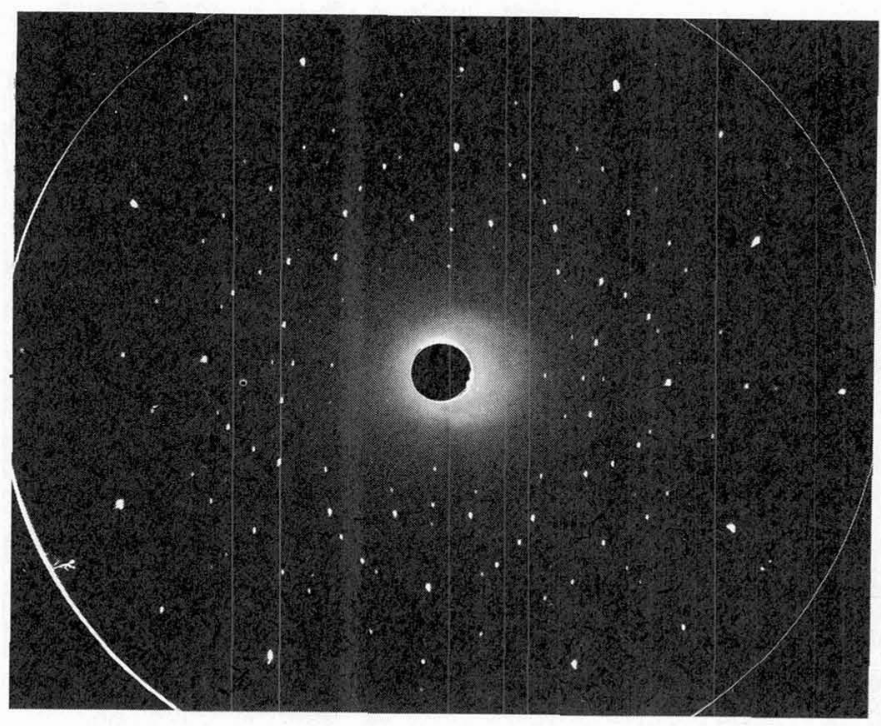

Fig.2 - Lave diffraction pattern of a $\mathrm{YBa}_{2} \mathrm{Cu}_{3} \mathrm{O}_{7-x}$ single crystal, beam parallel 001-direction. 
The sharpness of the spots is a measure for fluctuations of the orientation of subdomains. These are obviously small as can be seen in Fig.2 and it confirms the good quality of the single crystal.

The specimens for the field ion mass spectrometric analysis were prepared by mechanical means by selecting suitable fragments which were cleaved off from the different single crystals. Needlelike fragments were mounted on blunt nickel tips with a conducting, silver containing epoxy resin /8/. This was done under a stereo light microscope using a micromanipulator. The final alignement of the mounted tips was achieved by bending the nickel support needle in a suitable way.

Fortunately most of the needlelike fragments from the $\mathrm{YBa}_{2} \mathrm{Cu}_{3} \mathrm{O}_{7-\mathrm{x}}$ single crystals can be used directly for the atom-probe analysis without further electropolishing. For comparison a few tips were additionally etched in a commonly used electrolyte containing perchloric acid diluted in ethyleneglycol - monobutylether. The analyses were carried out in a pulsed voltage TOF atom-probe with an electrostatic sector $\left(163^{\circ}\right)$ and equipped with a vacuum lock for fast change of the specimens. For field ion imaging a channelplate screen assembly can be flipped in front of the tip. Hereby orientation and quality of the tips can be checked.

\section{3 - RESULTS AND DISCUSSION}

A uniform field evaporation behaviour can be observed which makes it possible to analyze the material with a pulsed voltage atom-probe spectrometer. The specimens have been kept at liquid nitrogen cemperature and pulse - dc ratios above 0.15 have been used. Only a few cluster ions have been observed. An atom-probe mass spectrum from one of the single crystal fragments is shown in Fig.3. In the spectrum signals corresponding to atomic and molecular oxygen, copper, barium, yttrium and oxides of copper and yttrium can be observed. This spectrum has been obtained after removal of more than 20 atomic layers and should be representative for the bulk. The elemental concentrations calculated from at least 2000 ions are in good agreement with the corrected results from electron microprobe measurements as well with the known stoichiometry.

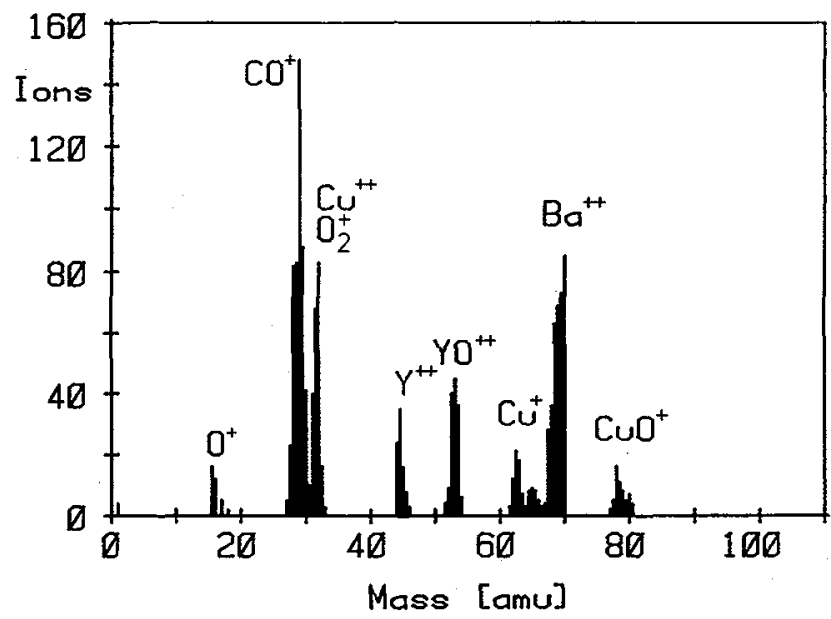

Fig.3 - Atom-probe mass spectrum from a $\mathrm{YBa}_{2} \mathrm{Cu}_{3} \mathrm{O}_{7-x}$ - single crystal sample after removal of more than 20 surface layers, orientation of the specimen parallel to c-axis. 
The spectrum also contains a rather large peak at $M / n=28$. We assume that this peak corresponds to $C O$. Besides hydrogen, $C O$ is a main component of the residual gas in the baked vacuum vessel. From ramped field desorption studies /9/ we know, that at a field of about $20 \mathrm{~V} / \mathrm{nm}$ the gas supply of the tip with $\mathrm{CO}$ is enhanced about a factor of 20 . The cut-off field (enhancement=1) has been observed at an electric field of about $30 \mathrm{~V} / \mathrm{nm}$. The dc-field during our analysis was typically kept at $20 \mathrm{~V} / \mathrm{nm}$, that means strongly enhanced CO-supply occurs. The cut-off field for $\mathrm{CO}$ (30 $\mathrm{V} / \mathrm{nm}$ ) lies noticeably above the evaporation field of the superconducting material which has been observed at 23-24 V/nm. A significant reduction of the co concentration in the spectra can be obtained when the analysis is done above the boiling point of Co according to the studies of $\mathrm{G}$. Zaharchuk et.al. /10/. In near surface layers also $\mathrm{OH}$ and $\mathrm{H}_{2} \mathrm{O}$ can be detected, probably because of the hygroscopic behaviour of this material. On etched specimens these signals have not been observed. Additionally, it is not easy to get a clear separation between molecular oxygen and doubly charged copper isotope ions, enveloping the oxygen signal. In further depth profiling analysis we focussed on the study of the local concentrations of yttrium and barium. The concentration profiles of the metal ions show distinct fluctuations which are obviously connected to the layer structure of the material. A good example of this is the autocorrelation - plot of the ratio $\mathrm{Ba}:(Y+\mathrm{Ba})$, which is depicted in Fig.4.

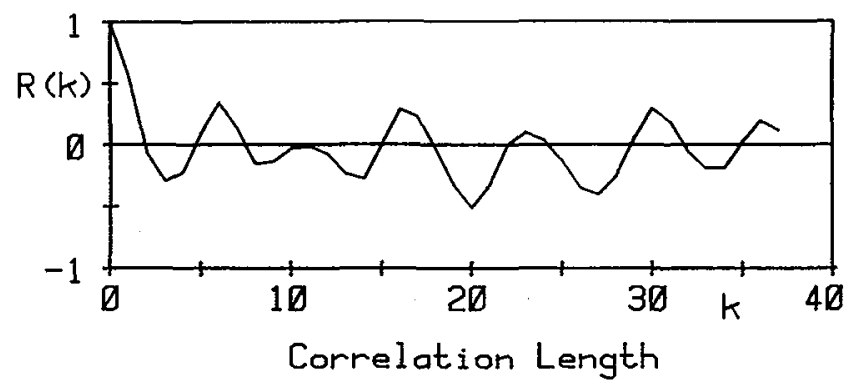

Fig.4 - Autocorrelation of the ratio Ba: $(Y+B a)$; calculated from the depth profile obtained from the same specimen from which the mass spectrum is plotted in Fig.3. (c-orientation)

The actual number of layers evaporated is obtained from the certain steps which occur in the online - plot of detected ions versus actuated desorption pulses due to the pile up effect. The separation of the maxima in the concentration of yttrium is found between 5 to 7 layers which is on the average in nice agreement with the actual 6 layers in the lattice.

In a crystallographic description of phases in $\mathrm{Y}-\mathrm{Ba}-\mathrm{Cu}-0$ superconductors, the existence of an orthorhombic phase of $\mathrm{Y}_{2} \mathrm{BaCuO}_{5}$ has been proved by Hazen et.al. /11/. This so called green phase is dispersed between the grains of the 1:2:3 phase in a ratio of about 1:3 in their sample. Striking is the very little difference in the lattice constants. For the $2: 1: 1$ phase (green phase) $a=3.859 \AA, c=3.904 \AA,(3 \times c=11.712 \AA) / 11 /$. For the $1: 2: 3$ phase $a=3.88 \AA, b=3.82 \AA$ and $\mathrm{c}=11.66 \AA / 12 /$. As already noticed above, a $1: 2: 3$ composition of the single crystals has been observed by electron microprobe measurements. In the transmission electron microscope sometimes very small lamina-like subdomains with different contrast can be observed. The thickness has been estimated to be below $10 \mathrm{~nm}$, a scale which stimulates to perform atom-probe measurements. In Fig.5 a typical depth profile of a cleaved off fragment from a $\mathrm{YBa}_{2} \mathrm{Cu}_{3} \mathrm{O}_{7-x} \mathrm{crystal}$ is shown. For simplicity only the ratio of $\mathrm{Ba}:(\mathrm{Y}+\mathrm{Ba})$ is plotted. The two dotted lines correspond to the $2: 1: 1$ - and the $1: 2: 3$ - phase. Most of the analyzed fragment samples show the same behaviour. 


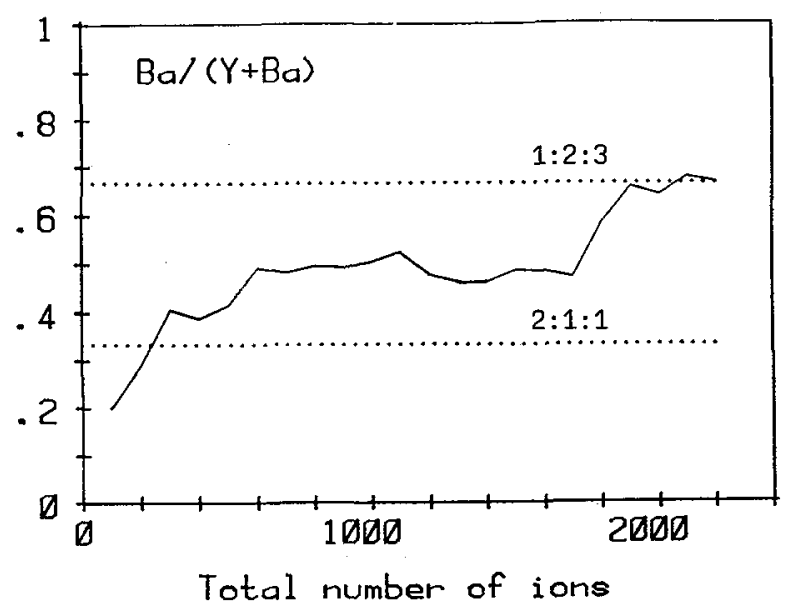

Fig. 5 - Ratio of $\mathrm{Ba}(\mathrm{Y}+\mathrm{Ba})$ versus depth, approximately 100 ions correspond to a depth of one atomic layer. Dotted lines indicate the $1: 2: 3$ and $2: 1: 1$ phases.

In a surface region of approximately 10 to 20 atomic layers in depth, the measured concentrations are closer to the composition of the $\mathrm{Y}_{2} \mathrm{BaCuO}_{5}$ - phase. After removal of about 20 atomic layers generally the composition corresponding to the 1:2:3 - phase as determined by the previous EDAX measurements is obtained. Excepting one sample, on this specimen both phases can be found in coexistence over the whole depth. The phase boundary was situated in axis in the centre of the tip. By turning the tip both phases can be probed one after another. We assume that our way of specimen preparation is selective in a special manner. If a small subdomain is embedded in the crystal, due to the little difference in the lattice parameters an internal stress will result. By trying to cleave the crystal, a fracture will obviously happen with a high probability at the phase boundaries. This would explain the atom-probe results obtained.

In order to improve the conditions for crystal growth $\mathrm{PbCl}_{2}$ has been added to the melt to act as flux medium. Hereby the question arises to what extend parts from the flux medium will be present in the crystal.

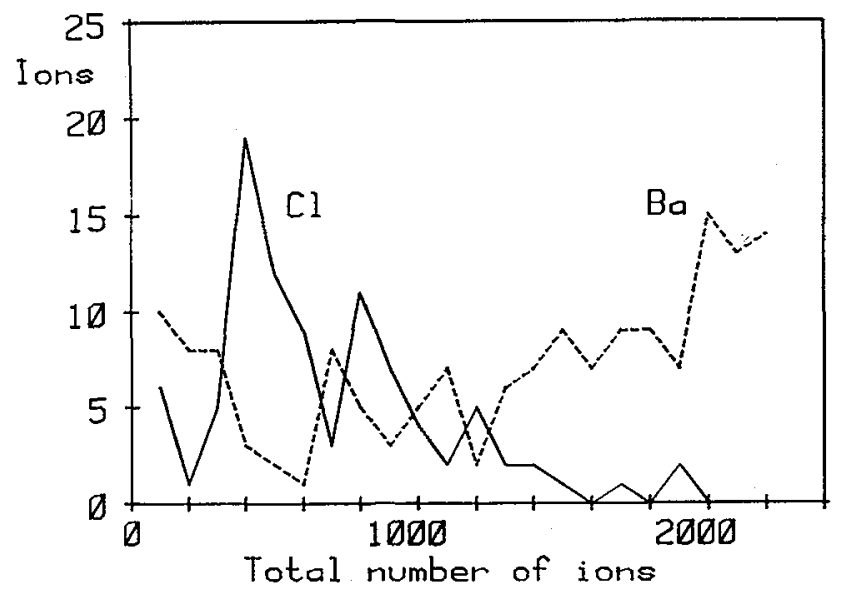

Fig. 6 - Concentration profile of $\mathrm{Cl}$ and $\mathrm{Ba}$ for a sample of a $\mathrm{YBa}_{2} \mathrm{Cu}_{3} \mathrm{O}_{7-x}$ crystal, grown from a melt containing $\mathrm{PbCl}_{2}$ as flux medium (200 ions per data point). 2 
On crystal samples grown with $\mathrm{PbCl}_{2}$ added, chlorine can be found in the atom probe spectra. The concentration profile for $\mathrm{Cl}$ and $\mathrm{Ba}$ is plotted in Fig.6. The concentrations of copper and yttrium show no significant variations. It should be noticed that in contrast to the profile in Fig. 5 the $Y$ - concentration does not vary versus depth. After removal of about 20 atomic layers the chlorine signals disappear completely in the spectra. The overall composition of this particular specimen as measured agrees more with the $2: 1: 1$ - phase. Unsolved is the question on wich lattice sites the $\mathrm{Cl}$-ions are sitting. The sites of Ba seem to be very unlikely because of the different electronic structure of these two elements. Other samples of the same charge show strong clustering during field evaporation. From the few samples investigated an improvement in crystal quality due to the added flux medium cannot be found.

\section{$4-$ CONCLUSION}

In the atom probe depth profiling analysis a second phase in the form of small laminas with a thickness of about $5 \mathrm{~nm}$ and with a composition very similar to $\mathrm{Y}_{2} \mathrm{BaCuO}_{5}$ has been found in $\mathrm{YBa}_{2} \mathrm{Cu}_{3} \mathrm{O}_{7-x}$ crystals, grown from a pseudoternary melt. After addition of $\mathrm{PbCl}_{2}$ as flux medium to the melt, $\mathrm{Cl}$ has been observed in near surface layers of cleaved off fragments, accompanied by a depletion of barium.

\section{ACKNOWLEDGEMENTS}

We would like to thank Dr.P.Golob and Dr.P.Pölt (Forschungsinstitut für Elektronenmikroskopie) for help with the EDAX-measurements and for TEM - imaging and Kristine Roth for providing the $X$-ray studies. This work was supported by the "Fonds zur Förderung der wissenschaftlichen Forschung" project number P7065.

\section{REFERENCES}

11) Wu,M.K. ,Ashburn, J.R. ,Torney, C.J. , Hor, P.H. ,Meng, R. L., Gao, L., Huang, Z. J. ,Wang, Q. and Chu, C.W. Phys.Rev.Lett. 58(1987) 908

12/ Kaiser,D.L.,Holtzberg,F.,Scott,B.A. and McGuire, T.R., Appl.Phys.Lett. 51(1987) 1040

/3/ Schweiger, E.,Leising,G., Roth, K., Leitner, O., Kahlert,H. and Pölt,P., Proc. E-MRS 1988 fall meeting, Strasbourg, will be published in J.Less Common Met.

14) Nishikawa, 0. and Nagai,M., Phys.Rev. B 37 (1988) 3685

/5/ Kellogg,G.L. and Brenner,S.S., Appl.Phys.Lett. 52(1987) 1851

/6/ Cerezo,A.,Grovenor, C.R.M., Hoyle, R.M. and Smith, G.D.W., Appl.Phys.Lett. 52(1988)1020

17/ Melmed,A.J., Shull,R.D.,Chiang,C.K. and Fowler,H.A., Science 239 (1988)176

18/ Melmed,A.J., J. de Physique 49-C6 Suppl.11(1988)67

19/ Rendulic,K.D. and Leisch,M., Surface Sci. 93(1980)1

/10/ Zaharchuk, G.,Alvensleben,L.v., Oehring, M., and Haasen,P., J.de Physique 49-C6 Suppl.11(1988) p. 471

/11/ Hazen, R.M. ,Finger, L.W. ,Angel, R.J., Prewitt, C.T ., Ross, N.L. ,Mao, H.K. , Hadidiacos, C.G. ,Hor, P.H. , Meng,R.L. and Chu,C.W., Phys.Rev.B 35 (1987) 7238

112/ Ishirawa, Y. ,Fukunaga, 0. ,Nozaki, H. and Tanaka, T., Japan J. Appl. Phys. Lett. 26 (1987)L676 